\title{
Catching up in securing excellence: the case of EUSOC in Central and Eastern Europe
}

\author{
by Martin Kreidl, Ivo Možný, Martin Potůček and Tomáš Sirovátka
}

\section{Introduction}

The usual and well-proven method of how to integrate the management of doctoral studies at an international level and to provide, by mutual control, for a sustained improvement in their quality, is to build open interuniversity international schools of graduate studies. Although such schools have mostly their seat at one specific university, they do not provide training for students of that university only. They are venues for regular meetings at workshops and seminars of not only graduate students from a number of universities, but also of their teachers. This generates synergies, helps to identify emerging trends, to formulate longterm research plans at the European level, and to build national and international networks of renowned researchers as well as researchers from younger generations. Such schools serve the $\mathrm{PhD}$ students as a platform for sharing and exchanging knowledge and for their fully entering into the scientific community. In the context of European comparative research in the social sciences, this forms a preparation to take part in international and interdisciplinary research teams, suitable to explore the crucial issues and challenges facing today's social sciences. Last but not least, such schools elevate the level of PhD programmes of the participating universities since they form an appropriate method for developing further comparative research and for fostering an advanced methodology in the social sciences.

Universities in post-communist Central and Eastern Europe (CEE) which are developing post-graduate programmes are in specific need to form similar platforms due to the deterioration of academic standards during the communist decades. Here, it is crucially important to redefine the social sciences and to educate qualified young researchers while avoiding further brain drain to the West. Although PhD students from the Czech and Slovak Republics, Hungary and Poland, for example, occasionally participated in some events aiming to bring together graduate students - such as summer schools organized by the Central 
European University in Budapest - no permanent platform for international research cooperation existed in Central Europe until 2005.

It was in this year, that the Graduate School for the Social Sciences (EUSOC) was established due to a trans-border initiative of the Faculty of Social Studies at Masaryk University in Brno (Czech Republic) ${ }^{1}$ and the International Institute for Comparative Government and European Policy in Berlin, ${ }^{2}$ speaking out for a consortium of Western European universities. The founders aimed from the very beginning at a regional focus of their initiative, to avoid an overburdening panEuropean approach at fostering qualified social science research. As a result, it was decided to focus on the Central (and Eastern) European region, including leading universities from Austria, the Czech Republic, Germany, Hungary, Poland and Slovakia.

In this report, we aim to assess the developments of $\mathrm{PhD}$ studies at five universities (predominantly of the Visegrad countries), reflected in the papers they presented at various EUSOC seminars. First, we will explain the aims and operations of EUSOC, followed by an analysis of the research presented by young researchers in key social science areas, including tentative comparisons with the state of social science research in Europe and beyond. As a result, we are shedding light on the emerging social science research in CEE countries, based on this sample of young researchers' outputs. Although $\mathrm{PhD}$ students from Austria and Germany also participated at the seminars, we kept the numbers small - to avoid an overflow of participants; however, these students formed an interesting control group insofar, as they "imported" the state of the art as currently to be observed in Vienna, Dresden, Chemnitz or Berlin. We cannot, of course, provide fully representative and reliable evidence on the current stage of social science research in the countries under consideration. Nevertheless, since we rely on a sample of papers, emanating from universities and research institutes ranking among the most recognised academic bodies in this part of Europe (and nearly 200 research papers by young researchers in four key social science disciplines as a matter of assessment), the findings might be considered an indication of the state of the art regarding social science research in Central and Eastern Europe.

1 Represented by the, then, acting Dean, Prof. Ivo Možný.

2 Represented by the Director of the Institute, Prof. Joachim Jens Hesse, who acted for the three Berlin Universities, securing access to the work of further graduate schools. He knew the area well, as he served as an adviser to major International Organisations after 1989 in re-establishing democratic statehood and the rule of law in the countries of Central and Eastern Europe. 


\section{The European Graduate School for the Social Sciences (EUSOC)}

\section{Institutional setting}

EUSOC is affiliated to one of the universities in the new EU Member States in order to coordinate activities in facilitating the crucial objective of the upcoming graduate schools: to assist in the fast qualitative advancement of $\mathrm{PhD}$ studies in the post-communist countries. The Faculty of Social Studies at Masaryk University in Brno serves this coordinating role. It is nowadays one of the leading faculties in social research in the region, whose revenues are created by about $40 \%$ through its research activities. The faculty provides a stimulating scientific environment for about $300 \mathrm{PhD}$ students of political science, sociology, social policy and social work, psychology and social psychology, environmental and, finally, media studies, being often involved in a broad range and variety of research projects. The participation of the other EUSOC-partner universities from Central Europe enabled to create a strong network of research oriented university bodies ambitious to integrate high methodological standards into their doctoral programmes and to cover most of the decisive fields in today's social sciences: sociology, political science, public policy, European studies, social policy and social work, social psychology and media studies. The partners of the regionally confined network are currently as follows: Faculty of Social Studies, Masaryk University, Brno; Faculty of Arts and Faculty of Social Sciences, Charles University, Prague; Institute of Sociology, Prague; Faculty of Arts, Comenius University, Bratislava; Faculty of Social Sciences, University of Vienna; Faculty of Social Sciences, Eötvös Loránd University, Budapest; Institute of Sociology, Jagiellonian University, Krakow; Institute of Political Science, Dresden University; Faculty of Arts, Chemnitz University of Technology; International Institute for Comparative Government and European Policy (ISE), Berlin.

\section{The aims}

The basic idea of the EUSOC programme is that most advanced studies in the social sciences share methodological procedures, similar in many respects and identical in their basic principles; their knowledge bases are overlapping, they often utilize identical data sources (and sets) as well as specific literature. The issues under research are often interdisciplinary in nature and cannot, therefore, be dealt with applying the routines of a single discipline. The social and political issues that the countries of Central and Eastern Europe, and specifically the Visegrad countries, are facing are by now rather closely linked to similar sets of 
issues faced by European societies at large; after the integration of the new Member States into the European Union, the problems faced by its individual members are becoming even more alike.

The overarching objective of EUSOC (to assist in the fast qualitative advancement of PhD studies) consists of a number of elements: to integrate postgraduate work at European universities as recognized programmes by creating networks of exchange of knowledge and competence among them; to open the door to international professional networks for its graduates; to prepare them for cooperation in international teams working on research projects of the European Union; and, not least, to create qualified personnel for teaching purposes at Central and Eastern European universities (and beyond). Excellent theoretical, analytical and methodological skills in social science research form a crucial prerequisite for according activities.

As a result, a solid theoretical background and a demanding methodology are viewed as crucial in establishing a platform for advanced interdisciplinary research, supporting the development of the individual social science disciplines at the same time. The choice of the (sub-)disciplines involved is compatible with this aim due to the close links between them.

Participation of first rank teaching staff from all partner universities represents a key device of EUSOC and form a further condition for achieving the mentioned objectives. The "regional roots" form another one: the school is deliberately intended as a Central and Eastern European unit with a strong regional focus, established as independent of EU funding during the formative years to secure a truly demand-driven approach.

\section{The operations}

The international and interdisciplinary (and in some cases even intercultural) seminars of EUSOC represent the main platform of its activities. The seminars are guided by a number of rules and procedures: early invitations to attend EUSOC seminars (EUSOC Sem) in the form of "calls for papers" that are sent out to doctoral students in the social sciences at member universities; seminars organised once or twice per year, mostly in Telč, allowing for in-depth discussions with invited students of no more than sixteen to eighteen per session. These students are invited after a selection procedure dealing thoroughly with the quality of the asked for papers - as far as transparent from the submitted material, especially so-called "extended abstracts". The final selection of participants is provided by a Steering Committee and based on an evaluation of EUSOC Fac- 
ulty staff members (appointed evaluators; currently Professors Hesse, Kreidl, Kucia, Možný, Nauck, Patzelt, Potůček, Rabušic, Richter, Rudas, Sirovátka and Szomolanyi). Not later than a month before each seminar, the finally selected students have to send their full texts to the EUSOC Sem secretariat. The secretariat in turn appoints supervisors for the individual contributions from the EUSOC Faculty members, and one of the attending students as referee. It is, of course, required that all participants read all papers before the seminar in order to prepare for the mostly intense three day-discussions.

\section{The results of EUSOC so far}

In the following, we aim to critically assess the quality and stage of development of key social science disciplines at the partner universities of EUSOC, as documented in the papers by young researchers submitted to EUSOC seminars during the formative years of the institution (from 2005 to 2013). We are confronting these developments with the trends and standards observed in specific social science disciplines in the other ("old") EU Member States and, of course, countries outside the EU. In doing so, we are concentrating on the thematic focus of the papers and research questions put forward as well as on the chosen methodological and empirical approaches.

During 2005 to 2013, there were all together 12 seminars (in 2006, 2007 and 2009 two seminars), at which young researchers submitted 195 papers. 67 of them were presented in sociology or overlapping disciplines, 41 in social policy and social work, 31 in political science, 21 in public policy and 15 papers in other social sciences, such as social psychology or media studies, management and marketing. We will assess the papers due to their main disciplinary orientation: sociology, social policy and social work, political science and public policy.

\section{Sociology}

Of the 67 papers that were considered of sociological relevance, 49 were finally accepted for a broader debate. Whereas the initial assessment was based on the inspection of the delivered material and provided abstracts, further deliberations, negotiations with the reviewers of other disciplines, and a more detailed inspection of borderline papers secured a cohesive set of proposals that forms the basis of this review. 


\section{Thematic focus}

Most of the papers dealt with traditional sociological topics such as family (11 papers), cultural sociology (including media studies, seven papers), social stratification and mobility (seven papers) and migration (five papers), but the theoretical approaches and the chosen conceptual frameworks often indicated significant departures from "tradition". These departures most often reflected current (to some observers also ardent) social problems. For instance, papers on issues of family sociology often linked family formation and fertility to labour market developments, employing a life-course perspective that is gaining increasing popularity in sociological research - or highlighted the importance of the workfamily balance/conflict. Similarly, while most of the stratification papers looked at standard topics (inter-generational educational and occupational mobility, poverty incidence), several others looked at newly emerging phenomena (precarious employment structures, inclusion/exclusion-mechanisms).

Papers in the area of cultural studies were rather diverse in their analytical outreach. We have seen work on consumption patterns in general or within in specific groups (such as the elderly or young ones), or students looked at specific aspects of developing popular cultures (like parasocial relationships between youth and "popstars"). Other topics included issues of identity building (e.g. through clothing and other symbolic means) and sharing (through memorial sites etc.). Finally, some papers studied culture as an instrument of political activism (e.g. feminism).

Migration papers were similarly diverse, ranging from case studies of specific groups (e.g. Ukrainians in the Czech labour market, the status and role of au-pair help) and life situations (e.g. migration as a reaction to marginalization) to a discourse analysis of public migration debates and a conceptual analysis linking irregular migration to security issues.

Unsurprisingly, there were several papers working on less traditional topics. These were represented by a set of contributions that could roughly be categorized as "gender, feminism, gay \& lesbian studies". These topics covered areas such as gender issues in schools and schooling, the social construction of gender in pornography, forms and limits to gay and lesbian parenthood, different modes of feminist activism. Another recent (and potentially innovative) contribution to sociological research was provided by the growing interest in the role and function of social capital and social network analysis. Only three papers dealt with issues of demographic changes, e.g. the ageing population. Given the recent emphasis of various political actors as well as public concerns on this issue, the 
modest interest of the young researchers formed a bit of a surprise.

Several classical sociological topics were indeed almost invisible at EUSOC so far. For instance, there was only one paper that dealt with the sociology of deviant behaviour (it looked at domestic violence), and a single paper on rural population in the Czech Republic could not patch over the lack of formal demographic analysis.

Finally, there were a few papers in this category that we failed to classify, among them a study in environmental sociology, one on the perception of corruption, two on sexual behaviour of adolescents, and a sociolinguistic exploration of sociological discourses.

\section{Methodological approach}

As regards the chosen methodology, most of the sociological papers used empirical data or proposed at least to do so at a later stage during the research work. Subdividing the detectable approaches, there were 11 purely conceptual contributions and one methodologically oriented paper. The empirical papers relied mostly on secondary data (19 papers), while 12 authors utilized their own (i.e. primary) data. Surprisingly, many contributions combined primary and secondary data (eight cases). ${ }^{3}$ The most frequent data-source were standardized surveys (14 cases). 10 papers relied on multiple data sources and another nine papers employed interviews. It furthermore surprised, that is was almost uncommon to base the research work on census data and other official statistics (only three papers). Few further contributions utilized texts as their primary data and employed either content analysis or critical discourse analysis during their research work. Finally, there was a single paper based solely on participatory observation.

Cross-sectional studies (31 papers) were the most commonly used approaches. Other designs were uncommon - there was one longitudinal study, a further one was based on repeated cross-sectional data, and three papers utilized retrospective measurement of life-events from a standardized survey. We were quite surprised that the increasing popularity and availability of panel surveys did not find a sizeable reflection among EUSOC participants.

Comparative approaches were infrequent, being used by 11 authors only. Several of the comparisons looked at whole societies/states, other focussed on specific

3 Cf. Jacobs, J. A.: Multiple Methods Articles in the American Sociological Review, in: Footnotes, 33/9 (2005). 
levels or sectors (residential areas, municipalities, rural/urban areas). Given the increasing popularity of comparative approaches, ${ }^{4}$ this again turned out to be a surprise.

Most authors employed a micro-sociological perspective and studied individual actors, their behaviour, attitudes and the like (31 papers). These studies tended to be based on data from a single country. Purely macro-sociological in nature were two papers comparing states. Several other contributions distinguished levels of analysis further and aimed at a kind of multi-level design (e.g. with individual actors being embedded in macro-level structures). The overall lack of truly comparative studies ought to be taken up in the next EUSOC seminar and should form a topic (and receive careful consideration) not only among the student body but within the Faculty, too.

\section{Social Policy and Social Work}

In post-communist countries, the sub-disciplines of social policy and social work as part of the university education had yet to be established after 1989. From the very beginning, they were strongly bound to the more established disciplines of sociology, economics and law (social policy) or psychology and sociology (social work). Although it is common at many EU universities to perceive social policy and social work as part of sociology programmes, they have developed as independent disciplines at several universities. In the Czech Republic, for example, there are two universities where $\mathrm{PhD}$ studies exist in social policy and social work (Public and Social Policy in Prague, Social Policy and Social Work in Brno). This might explain that the social policy stream has been the second most frequently asked for within the EUSOC programme, as $\mathrm{PhD}$ students in sociology or other social sciences often aim at subjects with a broadish social policy background; there have been more than forty (41) papers from the total number of 195 discussed at EUSOC seminars since 2005.

\section{Thematic focus}

Interestingly, the prevailing topics are associated with "new social risks". 5 La-

4 Cf. Jacobs, J.A.: Comparative and International Research in the American Sociological Review, in: Footnotes, 35/1 (2007).

5 Bonoli, G.: The Politics of the New Social Policies: Providing Coverage Against New Social Risks in Mature Welfare States, in: Policy\& Politics, 33/3 (2005), 431-449; Taylor-Gooby, P.: New Risks, New Welfare. The Transformation of the European Welfare State, Oxford, 2004. 
bour market related themes have been addressed in 10 papers, ranging from labour market flexibility, part-time working and the ageing workforce to a reconciliation of family and work, the problems of long-term unemployed, active labour market policies, and industrial relations broadly understood. Three other topics were more often addressed than others; this refers, first, to social services (six papers), such as crisis intervention (SOS children villages, child protection, HIV prevention), care for the elderly and care services in general. Secondly, the issue of social governance (again six papers), were of similar interest. Here, the cooperation of various social policy actors, services at the central and local government level, public-private partnerships, the influence of public sector institutions on investor's decisions, and forms and functions of local entrepreneurship served as key issues. The third topic had been formed by poverty issues, minimum income schemes and forms of social inclusion (five papers); it was here that national action plans on social inclusion were being addressed, the effectiveness of national minimum income policies investigated, and the contribution of NGOs in alleviating poverty within different welfare regimes analysed.

The second major group of topics was concerned with rather traditional social policy (addressing "old social risks") and social work issues: health care (three papers) with specific emphasis on user fees; the family (three papers) with emphasis on shaping family policies in general; social work (three papers) with an analytical concentration on the identity of social workers, the empowerment of drug users, and mediation policies pursued in social work and education. Further topics being raised by students under the social policy and social work umbrella were pensions, where the authors were dealing with justice in pension schemes and choices of the population in securing their future pension claims; education, addressing an elaborate evaluation framework; and, lastly, issues of justice and the impact of media on welfare state policies in comparative perspective.

The selection of the topics may not seem surprising. Labour market problems, unemployment, poverty and social exclusion represent basic challenges for almost all market systems in Central and Eastern Europe and have been subject to significant attention within the policy-making systems; especially the institutions developed to employ new policy schemes attracted academic research from the early 1990s onwards. Similarly, the area of social services faced a fast development in the sense of a qualitative shift from state dominated institutional service provision towards a public-private mix, putting emphasis on quality standards, users' choice and efficiency. A "governance" perspective has become important as well due to the process of social services transformation and the challenge in 
establishing effective cooperation and co-ordination among and between the public, private businesses, and actors in the non-governmental sector of most policy areas.

To sum up, the choice of the topics seemed to cover most of the issues that are central not only to the still transforming societies in Central and Eastern Europe but also forming new social risks, policy challenges and "social investments" in a more general context. On the other hand, one may discover that there is a kind of neglect of topics that ought to be of increasing relevance for current social policy research; this refers to the ongoing process of Europeanization, the attempts at harmonizing social security standards, and of utilizing new available instruments, such as the method of open coordination - especially from the perspective of new EU Member States. The so far missing sustained interest of the EUSOC student body in these issues mirrors the other gap that has already been mentioned: the only lukewarm interest in transnational and comparative studies of public and social policies; it should not come as a surprise that the interest in applying the subsidiarity principle in providing social services is gaining ground. ${ }^{6}$

\section{Methodological approach}

The methodology used in the papers on social policy and social work has been very much driven by traditional sociological or political science approaches rather than by specific instruments, such as evaluation research (implementation or impact studies) or policy analysis (focussing on the actors and stages of the policy-making process), or in fact comparative studies of national welfare systems. While comparative studies seem to form the prevailing trend in leading journals of social policy and social work worlwide, there were so far only eight comparative analyses presented within EUSOC's social policy/social work stream, most of them based on two country-comparisons, only one aiming at an EU wide investigation.

Similarly, while the usage of mixed research methods is common in social policy due to the complexity of the problems that typically require multidisciplinary approaches and the exhaustion of several data sources available (complementing the gaps in one data source by another source and similar), only seven papers were based on a mixed methods approach. The prevailing attitude aimed at ex-

6 Cf. Sirovátka, T./Tomešová Bartáková, H.: Reconciliation Policy in the Czech Republic and the EU. From Neglect to Rejection, in: European Journal of Social Security, 10 (2011), 161-177. 
hausting various qualitative methods (18 papers), such as institutional policy analysis, document and content analyses, interviews, the setting up of focus groups, participatory observation etc. Nearly all these papers attempted, however, to frame the qualitative evidence with a broader problem analysis and have used secondary data, statistical descriptions and various policy related documents to contextualise the research question and the findings. Most of them also aimed at combining several qualitative techniques. What has been missing in quite a number of these papers was a thorough exploration of the "contested territory", meaning to exploit the options to contextualise and generalise the findings appropriately. Finally, there were nine papers based on serious quantitative work and the use of available paradigm(s). Here, typically large survey data, such as SILC, LFS and Census, or specific surveys, like ESS and ISSP, were exhausted, mostly complemented by administrative or other data.

The prevailing inclination to engage in qualitative research makes, of course, comparative studies more demanding, since it is clearly more difficult to operationalise robust comparative criteria for national case studies due to the importance of the national contexts. As a consequence, we have identified "good practice" of comparative research rather among the papers based on quantitative methods. Some of them were indeed quite advanced in their methodological grounding and provided interesting findings. These examples are possibly documenting that despite some apparent deficits there is encouraging methodological progress in social policy research as well. Several papers have shown the ability of young researchers to carry out enhanced comparative research by analysing large data sets and in employing advanced statistical methods. It was, thus, possible to analyse different welfare regimes among the Visegrad countries and to use the LFS pulled design sample to analyse transitions between full-time jobs, temporary contracts, part-time employment, short-time unemployment, longterm unemployment and inactivity in specific studies of labour markets. For the Czech Republic, for example, a high degree of labour market rigidity was being detected when comparing it to most of the EU-15 countries. Another study dealt with the question whether flexible (part-time) jobs may serve as an alternative to unemployment or the deterioration of earnings under crisis conditions - or whether it might lead to underemployment (involuntary part-time working) only. The analysis was based on the Fourth European Working Conditions Survey (EWCS) from 2005 (a sample of 30.000 individuals). The ambiguous character of part-time work got confirmed as well: some categories of workers are moving between unemployment and underemployment whilst some other groups may be 
rather profiting, gaining better jobs, such as women after parental leave. Such findings represent a warning to adopt to simple solutions/policies for the labour market, aiming to implement more flexibility into labour contracts.

Finally, some papers used modelling methods: one compared family policies in the EU while using the Model Family Method suggested by Bradshaw and Finch $^{7}$, focusing on the amount and composition of child benefit packages (CHBP), specified for various households types, economic activities of households and earnings. The paper showed that in spite of common welfare traditions Slovakia, for example, continues to resemble Conservative regime countries, while the Czech Republic is rapidly abandoning previously universal and generous social-democratic policies. In another study the attitudes towards the justice of pension schemes were examined by using data from the International Social Justice Project (ISJP), where the block on pensions was added. The respondents assessed the degree of "justice" with the help of vignettes representing various types of beneficiaries, characterised by several variables; 250 combinations, grouped into 25 vignettes, were analysed by multilevel modelling: previous income, the actual pension, years spent in workforce, living with a partner or alone, and the number of children have had a strong impact on the idea of "fair pension" meaning that merits were obviously considered as the first principle of justice.

\section{Political Science}

Within the Central and Eastern European countries, political science ranks among the young disciplines as well, as it was only after 1990 that political science was called among the established social sciences, from the very beginning inspired by the international standards of the discipline at large and also by domestic traditions of close disciplines, such as history, law and sociology. Today, political science seems to be rather attractive to the student body, encouraging a further professionalization of the discipline.

\section{Thematic focus}

The total of 31 papers presented within the political science stream of EUSOC may be clustered into six groups. The first one was represented by election (behavioural) studies (three papers), studies on parliamentary and political systems (four papers) and work on specific transition/transformation-policies towards 
democratic statehood (two papers). The second group was composed of studies on ethnic conflicts (five papers) and politics of migration (four papers), whereas the third group consisted of rather general or theoretically oriented contributions (five). In the fourth group security issues built the focus (four) while in the fifth group foreign relations issues (three) resp. EU-policies (three) were at the forefront of the interest. There has, of course, been an overlap between these groups, but it might make sense to subdivide them to indicate the rather impressive range of topics falling under the heading of "political science".

In this stream of EUSOC activities, students from Austria and Germany had been more frequently represented than in the other streams (12 out of 31), without, however, forming a different kind of student body. It was remarkable to observe that during the later seminars differences in theoretical interests as well as analytical approaches between German and Austrian students and those from the Visegrad countries were clearly narrowing, another indication of the encouraging progress of social science education within the Central and Eastern European countries.

As regards election studies, the following issues were discussed in detail: the structure of electoral behaviour, the stability of party closeness in post-election surveys, and the impact of communication networks on electoral preferences. Concerning parliamentary and party systems, there were papers on the Italian party system confronted with the perspective of bipartism, on the causes of parliamentary party unity, on coordinating control through parliamentary business committees as a key to parliamentary strength and, eventually, the issue of religious language as a political tool as visible in presidential election campaigns.

The specific issues of transition from communism to democratic systems led to papers on the institutional framework of corruption, modes of public procurement in the Czech Republic, and the problem of how to deal with the communist past through lustration policy in Visegrad countries.

The papers on ethnic conflicts paid attention to such diverse issues as the role of national mythology as an ideological tool in Slovakian politics, the causes of ethnic conflicts in the Caucasus region, cultural cleavages in European democracies, the Islamic opposition in the political systems of Arabic countries, and the institutional frame of minority rights protection in Romania, while the papers on migration issues discussed the impact of migration on the politics of Austrian parties, the role of national identity in the German migration discourse, the perception of foreigners in opinion polls in the Czech Republic, and the economic 
requirements on naturalisation in different welfare state regimes.

Whereas security-centred analyses focused on the consequences of Balkan conflicts for security policies in Austria, security threats for Albania, and counterinsurgency strategies, foreign policy/international relations papers dealt with the topics such as political relationships between Ukraine and Poland in the past and present, Russian international policies concerning the Kaliningrad area, and the construction of Ukraine-EU relations. Specifically EU-centred perspectives examined the adaptation of federal as well as unitary (political) systems in the accession process, the political role of translation in constructing EU-institutions, and the repercussions of the enlargement process on institutional change in the EU institutions themselves (Council and Committee of Representatives).

A few purely theoretical papers were dealing with theories of justice, political communication and its impact on the public, international legal compliance theories, anarchism and absolutism in the writings of Max Stirner, and rebellion as a philosophical category.

\section{Methodological approach}

There were seven papers out of 31 based on an explicitly comparative methodology: one of them presented a cross-sectional and time-series bound EU-wide comparison of election results, others compared a limited number of selected countries (case studies method) in studying the determinants of parliamentary party unity in the EU countries, America and Asia. Further papers looked at the link between welfare state development and economic requirements for naturalisation in Western EU countries, cultural cleavages, and the emergence of Islamic opposition in different Middle-East environments; they furthermore provided an assessment of lustration-approaches in Visegrad countries and compared variations in election results.

As regards the outreach of the contributions, seven papers aimed at EU level issues, two looked at global problems and 16 concentrated on national political problems.

In doing so, the qualitative paradigm clearly prevailed (in 18 cases out of 31 ), in only three papers the evidence was basically quantitative (election studies), and four papers used mixed methods and data. The qualitative studies approached their topic mainly via an institutional orientation, be it of an historical, evolutionary, actor centred, sociological, and/or discursive nature; sometimes constructivism played a role. Often the empirical evidence combined some kind of historical 
and institutional analysis, discursive analysis, content and critical discourse analysis, supplemented with basic statistical information. Secondary analysis of the existing sources has plaid a crucial role as well.

The quality of these methodological underpinnings varied to a large extent. Several authors used almost exclusively secondary sources, mostly due to early stages in their research process. The papers where the authors used mixed methods were, however, sufficiently complex in their approaches: one study, for example, designed a plan of a sophisticated combination of historical institutional analysis and qualitative comparative methods (QCA), as developed by Ragin and in order to examine the causes of parliamentary unity in several EU countries. Another study suggested to combine institutional analysis with quantitative indicators of electoral turnout in comparing the emergence of inner-Islamic opposition. A further approach consisted of a combination of survey data (opinion polls) with content analysis of media presentations to examine media discourse effects on the attitudes towards migration and the integration of migrants.

Although there were, as mentioned, only three papers based purely on quantitative methods, they seemed to be quite advanced in their methodology. One contribution, for example, developed and applied a specific Structural Equation Modelling approach to study various effects (mobilising effects, polarising effects) of communication networks on the Hungarian electoral results. Another study used an extension of the Bayesian statistical model $^{8}$ in order to study transitions in electoral behaviour on the individual level during 1992-2010.

\section{Public Policy}

Although there were some social science issues being explored in communist Central and Eastern Europe that were in fact public policy proposals and related research since the 1960s, it was not before the early 1990's that the (sub-) discipline got established in the area. ${ }^{9}$

The then created Department of Public and Social Policy at Charles University in Prague became the institutional core of instruction and research in public policy. The first master students were admitted in the academic year 1993/1994, followed by the accreditation of a doctoral program of public and social policy and

8 King, G./Rosen, O./Tanner, M.A.: Binomial-Beta Hierarchical Models for Ecological Inference, in: Sociological Methods and Research, 28 (1999), 61-90.

9 Cf. Potůček 2007. 
the corresponding admittance of doctoral studies in the academic year 1996/1997. During that early period, the only other nucleus of public policy (research and teaching) in CEE countries originated at the University of Economics in Budapest. As a joint venture of Czech, Hungarian, Slovak and American authors, the first international public policy textbook for Central and East Europe was published in 2003. ${ }^{10}$ Two years later, this textbook was largely updated and adjusted to Czech usage. ${ }^{11}$ The number of master and doctoral study programmes in the area has been slowly increasing since, universities and public policy research institutes started to employ new graduates, and other textbooks in corresponding languages have been published ${ }^{12}$.

Today, public policy is developed rather broadly as a discipline that works through (and applies) explanatory frameworks of sociology, economics, political science, law, and theories of management - for the sake of analysing and forecasting the processes of shaping and asserting public interests associated with differentiated social problems. Public policy is chiefly involved in the institutional mediation of these processes by (and for) the public, civic, and partly also commercial sector(s), in a way usable for political practice. ${ }^{13}$

The disciplinary borders between public policy and other social sciences are relatively fuzzy. The students are being taught that cognitive problems should define the chosen approach, which demands epistemic tolerance and plurality. Thus, the selection of 21 public policy papers out of the wide range of those nearly 200 discussed at EUSOC seminars since 2005 was to some extent arbitrary. On the other hand, this proportion corresponds to the position of the discipline among other social sciences as represented in the EUSOC study program.

\section{Thematic focus}

Three papers out of those 21 focused primarily on the development of a theoretical framework, without explicit reference to empirical research. They dealt with the concept of philanthropy, applied a metaphor in conceptualization "liquid social movements", and offered theoretical discourse on various sub-streams of evolutionary institutionalism.

10 Jenei, G. et.al.: Public Policy in Central and Eastern Europe: Theories, Methods, Practices, Bratislava, 2003.

11 Potůček, M. et.al.: Veřejná politika, Praha, 2005 (2010).

12 E.g. Maliková, L.: Verejná politika: aktéri a procesy, Bratislava, 2003; Klus, M.: Verejná politika. Priestor, Efektívnost', Nástroje, Nové výzvy, Sládkovičovo, 2007.

13 Potůček, M. et.al.: Veřejná politika, op.cit., 21. 
Not surprisingly, six papers were attracted by the process of Europeanization in general, and in the accession of post-communist countries in particular. Three of them analysed decision making processes (coordination of and within EU policy making, the way of decision-making in the Council, and the role of European Space Policy in a European security concept). The other three studied the role of actors in the policy process. They asked how consistent elite and mass attitudes toward the European integration process are, how the partnership between the European Commission and interest groups works (or does not work), and what factors influenced the attitude of Austrians towards EU enlargement most.

There were two papers broadening the pool of doctoral students from outside Central Europe as well. The first conceptualized the relationship between state, business and the civic sector in Kyrgyzstan, whereas the second considered the ways and means of reforming bureaucracy in Ghana. Issues of global governance were visible only in a paper analysing the origins and long-term effects of policies to counter terrorism.

Five papers followed specific social problems associated with the transformation of post-communist societies, and looked at corresponding policy reactions. Among the chosen topics: the position of the father as provider before and after divorce, motherhood as a risk on the labour market, the transition from youth to adulthood under conditions of unemployment, and the social representation of mentally ill people. The last paper in this group analysed family policies as reflected in the discourse of Czech political parties.

Four remaining papers dealt explicitly with party political and administrative processes. One paper applied the theory of agenda-setting on the data from a national cross-sectional survey to test its validity (and came up with an attempt at theoretical fine tuning). Two papers provoked the EUSOC audience by questioning whether journalism may act as an instrument of mediation, and by asking for "best practise" in fighting juvenile crime, whereas the last paper observed political parties' strategies in the Slovak municipal elections.

As the various contributions embodied different stages of thesis preparation, one should have expected different levels of their theoretical grounding. And indeed, three papers presented theoretical groundwork exclusively, but all of them, along with another six papers, did it in a very satisfactory way. In contrast, nine other papers were to be characterized as more or less mediocre: the selection of theories was not supported by persuasive argumentation or their correspondence with the solution of a defined cognitive problem had to be questioned. Poor or no 
theoretical considerations were presented in three cases.

\section{Methodological approach}

EUSOC public policy students prefer qualitative methodology - 15 out of the 21 papers relied on it. The majority of papers combined several methods. The most frequently applied (five or six times) consisted of case studies, interviewing, and institutional as well as discourse analysis. Document analysis and comparative analyses in the stricter sense were used three times. One paper was inspired by the logic of metaphor.

Just three papers applied quantitative methods (using large representative surveys). Two others tried a mixed approach. One paper got by with an exclusively theoretical discourse.

In sum, the group of public policy papers was very diverse in terms of research topics, the ways to deal with them, and their academic quality. However, the variety and combination of methodological approaches provided for interesting results. One paper, for example, applied and further developed the theory of agenda-setting in order to better understand the mutual relationship between media and the public. The causal mechanisms of the agenda-setting approach were complemented with concepts of memory traces and trust in media. This theoretical framework got tested on the representative cross-sectional survey of individuals and a corresponding dataset from monitoring main TV news. Although the assumptions of the significance of media recipients' individual odds and individual priorities failed, the test confirmed the concept of memory traces, which could be enriched (instead of the above mentioned failed concept) by incorporating the rule of marginal utility.

Another paper provided a comparative analysis of the origin, nature, and stability of co-ordination processes in the European Union, ASEAN, and MERCOSUR while conceptualizing international regional organisations as frameworks for policy co-ordination by defining two co-ordination axes, horizontal (between the several member states), and vertical (between the international regional organizations and their member states). The extended qualitative research (analysing documents, interviewing responsible officials) confirmed the hypothesis that institutional design which provides for the high levels of interdependence between hierarchically independent actors and "incrementalist mechanisms" (such as via a court or arbitration) is likely to lead to stronger patterns of horizontal and vertical co-ordination in policy implementation. The EU proved to dispose of more effective co-ordination mechanisms compared to MERCOSUR; MERCO- 
SUR, in turn, performs still better than ASEAN in this respect.

A further paper presented a well-informed overview of various streams of institutionalism (namely neo-institutionalism and historical institutionalism) in policy analysis, submitting it under the notion of "evolutionary institutionalism" as it deals with institutional reproduction, variation, selection, mutation, and institutional niches. This theoretical approach was applied to identify and indicate the shortcomings of weak and failing states and the negative consequences for the international policy practice. The innovative, articulate suggestion of how both public policy research and practice could benefit from evolutionary institutionalism provoked a lasting debate within the student body and the EUSOC Faculty.

\section{Conclusions}

EUSOC has clearly succeeded in creating an interdisciplinary graduate school in social research with considerable impact on the quality of the presented $\mathrm{PhD}$ research projects. It has provided a stimulating environment for young researchers at CEE Universities during the last decade. It has, furthermore, contributed to the improvement of theoretical, analytical and methodological standards in postgraduate studies across the disciplines of social science at the participating universities.

These encouraging results are confirmed in the student assessments regularly carried out at the end of the seminars. About $90 \%$ of the student body considered the participation in the seminar as "very useful", the rest as "somewhat useful". All of them welcomed the intense feedback they received to their presentations, from both Faculty members and fellow students, and stressed the unusual "team spirit" that characterized the meetings.

The individual papers submitted to EUSOC's international seminars have documented some interesting trends: First, comparative studies (and the methodology to engage in those) are still somewhat underdeveloped in Central and Eastern European social science research. Second, the qualitative paradigm clearly prevails over quantitative one(s), despite (almost) excellent skills in the analysis of quantitative data. Third: So far, there is hardly interdisciplinary work to build upon, limiting the student capacities to engage or to take part in comparative and applied research. It might be useful to address all three issues during the years to come, as the ongoing Europeanization process will ask for an accordingly broadened education.

The participation in EUSOC was conditioned by the success in a competition, 
based on the evaluation of written research proposals. Most of the successful students showed a high academic potential and determination to pursue their work further. It should, therefore, not come as a surprise, that some of them are by now our young colleagues, as lecturers or researchers at the participating or other (regional) universities or research institutes. This is probably the most telling success indicator of EUSOC's achievements - as a minor but important part of the historically unique transformation process of Central and Eastern Europe since 1989. 